\title{
Animalidade: signo cego, espaço negro
}

Eduardo Jorge

UFMG / Capes

\begin{abstract}
RESUMO
O presente ensaio discute os aspectos formais da semelhança e da animalidade tomando como ponto de partida a obra plástica e literária do escritor brasileiro Nuno Ramos.
\end{abstract}

\section{PALAVRAS-CHAVE}

Semelhança, animalidade, metamorfose, literatura, arte contemporânea

Nuno Ramos ${ }^{1}$ escreveu em Cujo que “a semelhança é o melhor disfarce”. Publicado em 1993, a obra mais parece um conjunto de notas de ateliê, resultado de observações da transformação da matéria que, mesmo sendo fruto de um olhar próximo, meticuloso, compõe uma distância elaborada pelo artista e escritor.

A distância talvez seja uma partilha da escritura com a experiência plástica, pois as notas de Nuno Ramos estão envolvidas com os procedimentos materiais de manusear a matéria. Assim, é no modo de manusear a escritura que Nuno Ramos convoca essa distância ao criar uma aproximação tátil com a escrita, embora a relação proximidadedistância na anotação de Nuno Ramos seja deslocada para a questão da animalidade, que será discutida enquanto operação crítica.

A condição aforismática de Cujo levanta a suspeita de uma escrita na condição de abandono, tal como o ateliê, uma vez que as luzes são desligadas, as portas fechadas e todo material convocado pelo artista em um dia de trabalho repousa, mas se transformando. Cujo é uma referência a algo anterior e que oferece uma noção de continuidade sintática, mas

\footnotetext{
${ }^{1}$ RAMOS. Cujo, p. 71.
} 
nesse caso Cujo é uma interrupção, uma descontinuidade ou ainda uma "semelhança informe”.

“A semelhança não é um meio de imitar a vida, mas uma forma de torná-la inacessível, de estabelecer um duplo fixo que escapa à vida.”2 Essa é a operação de Maurice Blanchot em L'amitié. Blanchot refere-se à semelhança como um modo de captura da vida imediata, do tempo efêmero e que entre a captura daquilo que é efêmero e um verniz que garanta sua duração existe uma ausência que se reconverte em semelhança.

Enfim, por que recorrer à semelhança para abordar a animalidade? Seria de fato a semelhança o melhor disfarce? A animalidade relacionada à semelhança atuaria como um dos "próprios do homem", para utilizar um dos termos de Jacques Derrida. Ou ainda, segundo Walter Benjamin, em “A doutrina das semelhanças”, “é o homem que tem a capacidade suprema de produzir semelhanças”. ${ }^{3}$ Produzir semelhanças, isto é, um disfarce, formas de encobrir, ocultar, enganar, alterar, mudar, enfim, apagar as marcas próprias, sua assinatura, falsificar-se para adquirir uma "aparência animal”. Nesse contexto será que a aparência seria uma forma de limitar o campo da literatura e das artes visuais na sua relação com os animais e a animalidade? Em termos de imagem (plástica, literária), como pensar a semelhança e a aparência?

"Diante de Lascaux, o homem civilizado volta a ser homem de desejo.” Eis o título de um dos ensaios de Georges Bataille que consta numa publicação póstuma que reúne seus ensaios redigidos entre 1944 e 1961. Para Bataille, o homem disfarçava sua humanidade sob as máscaras animais e, com isso, a própria animalidade era denegrida. ${ }^{4}$ Georges Bataille $^{5}$ afirma que desde muito cedo, ainda enquanto jovens, aprendemos a ver no animal aquilo que falta e na palavra besta aquilo que nossa escassa razão nos dava vergonha. É por isso que em Lascaux ou la naissance de l'art, Bataille ${ }^{6}$ apresenta a animalidade como um “signo cego” e, por isso, “um signo sensível da nossa presença no universo”.

\footnotetext{
${ }^{2}$ BLANCHOT. La amistad, p. 36.

${ }^{3}$ BENJAMIN. A doutrina das semelhanças, p. 108.

${ }^{4}$ BATAILLE. La felicidad, el erotismo y la literatura, p. 264.

${ }^{5}$ BATAILLE. La felicidad, el erotismo y la literatura, p. 263.

${ }^{6}$ BATAILLE. Lascaux ou la naissance de l'art, 1996, p. 11.
} 
Talvez uma semelhança imemorial esteja em vigor no campo de tensões entre o homem e o animal no pensamento, na literatura e nas artes visuais. A presença de um "signo cego" talvez se aproxime da "semelhança” empregada por Maurice Blanchot, enfim, aquilo que torna a vida inacessível. Por esse viés, a animalidade começa a ganhar corpo. Começa, porque seu corpo talvez fique em um estado intermediário, em uma zona de metamorfoses, em um "vai-e-vem das formas". 7

O movimento de Cujo segue para outro livro de Nuno Ramos, O pão do corvo. Na narrativa "O velho em questão", Nuno Ramos ${ }^{8}$ disfarça-se pela semelhança, embora mantenha o “corpo viscoso e provisório”, um corpo intermediário, intermitente, informe: "Quando foi que amei o intermediário, corpo viscoso e provisório, nem fome nem alimento? Quando foi que virei um cão sarnento e me tornei um lobo, quando foi que me tornei a praia?” O corpo se insinua ao ambiente, a animalidade seria morfológica ou ainda esboçaria similitudes estruturais, montando uma espécie de “espaço negro”. "Espaço negro” é a expressão utilizada por Roger Caillois ${ }^{9}$ em “Mimetismo e psicastenia” para designar a indistinção entre organismo e meio. A animalidade, portanto, coincidiria com “o retrocesso da vida em um grau”. Mas, em termos de animalidade, poderíamos falar em retrocesso? Para explicar melhor o "espaço negro" em termos de procedimento literário, o próprio Caillois ${ }^{10}$ expõe que:

O desejo de assimilação ao espaço, de assimilação com a matéria, aparece com freqüência na lírica: é o tema panteísta da fusão do indivíduo no todo, tema o qual precisamente a psicanálise vê a expressão de uma espécie de saudade do inconsciente pré-natal.

Será que essa “saudade” de um “inconsciente pré-natal” não seria a busca de um laço perdido entre o animal e o homem? Distância que inúmeras vezes procura ser preenchida pelo “signo cego” da animalidade. Na narrativa de Nuno Ramos, esse desejo reitera a sedução espaço-material que, por exemplo, pode ser conferida em As tentações de Santo Antão, de Gustave Flaubert, segundo a leitura de Roger Caillois: “penetrar em cada

\footnotetext{
${ }^{7}$ DIDI-HUBERMAN. La ressemblance informe ou le gai savoir selon Georges Bataille, p. 175.

${ }^{8}$ RAMOS. O pão do corvo, p. 19.

${ }^{9}$ CAILLOIS. El mito y el hombre, p. 123.

${ }^{10}$ CAILLOIS. El mito y el hombre, p. 130.
} 
átomo, descender ao fundo da matéria, ser a matéria”. ${ }^{11}$ Esse desejo de "retroceder a vida em um grau”, de cair no "espaço negro" ou agir sob o "signo cego", permanece enquanto disfarce em Nuno Ramos, ${ }^{12}$ nos seguintes excertos:

Sei que não vou ficar muito tempo assim e meu corpo, como um país estrangeiro, vai se encher de pelos, ou a casca rugosa, empedrada de uma tartaruga, ou os veios úmidos de um tronco escuro e antigo, ou a floração musgosa de alguma planta frágil.

Vem mais uma noite e entre todos os animais que sou eu sou aquele animal que dorme, nunca lembro do sonho mais sei que durei mais um dia. Toco então o elemento em que me transformo, às vezes porque quero, às vezes não.

Durante a narrativa de Nuno Ramos ${ }^{13}$ há uma interrupção, e a ruptura nasce de um desejo de lembrança dos sonhos: "Não queria me transformar mais uma vez, não depois de um intervalo tão pequeno. Precisava dormir na forma humana, tentar lembrar dos sonhos que tive.” Diante de todo o legado da psicanálise, e a partir de Nuno Ramos, ousaríamos dizer que o homem é um animal que sonha? ${ }^{14}$ Ou o sonho seria mais um dos "próprios do homem”, assim como os demais elementos diferidores tais como a palavra, o futuro e a própria finalidade da vida.

A finalidade da vida humana, para Sigmund Freud, em O mal-estar na cultura, jamais obteve uma resposta satisfatória. Entretanto, seria a ideia de uma finalidade que contribui para uma separação entre homens e animais. A finalidade dos animais, nesse sentido, seria a de servir ao homem. Mas, segundo Freud, ${ }^{15}$ isso não se sustentaria, pois o homem não sabe o que fazer com muitos animais - “a não ser descrevê-los, classificá-los e estudá-los -, e inúmeras espécies animais escaparam inclusive dessa utilização, pois viveram e se extinguiram antes que o homem as tivesse visto”. Descrever, classificar e

${ }^{11}$ CAILLOIS. El mito y el hombre, p. 130.

${ }^{12}$ RAMOS. O pão do corvo, p. 20, 22.

${ }^{13}$ RAMOS. O pão do corvo, p. 25

${ }^{14}$ Em “Recobrimento, lama-mãe, urgência e repetição, cachorros sonham?”, narrativa de Ó, Nuno Ramos (p. 148) prossegue com uma "investigação" sobre os sonhos de animais, mais precisamente o dos cachorros: "Sei explicar a origem das escamas, a finalidade do pâncreas, a energia resultante da explosão e da pedrada. Sei quantos pássaros vivem na mata neste exato momento. Mas nada disso, justamente porque sei aquilo que sei, é tão intenso quanto o abanar de uma cauda."

${ }^{15}$ FREUD. O mal-estar na cultura, p. 61-62. 
estudar o animal seria, portanto, um gesto desorientado do homem frente à quantidade de espécies que ele tem diante de si? Frente a essa questão, talvez exista uma tarefa sutil da filosofia, que se resume, grosso modo, em separar o homem do animal. Tarefa que pensadores como Michel de Montaigne, Georges Bataille, Jacques Derrida, Gilles Deleuze e Félix Guattari de algum modo intervieram na episteme que delibera uma fronteira, e a literatura, por esse viés, prolonga esse ethos pela poesia que capta um pensamento ou um instinto animal.

O instinto animal não é um mecanismo, como afirmou Georges Canguilhem, ${ }^{16} \mathrm{em}$ Escritos sobre a medicina, ${ }^{17}$ mas um conhecimento por imagens. A partir do aspecto fisiológico apresentado por Canguilhem, não podemos pensar a literatura e as artes visuais, em suas aproximações e distanciamentos, como um conhecimento por imagens? Esse seria outro modo de articular o instinto ou ainda "o signo cego" da animalidade. Não seria sob este signo que Nuno Ramos sairia da pausa confortável do sonho para voltar ao contato do animal com a escritura? É retornando a narrativa “O velho em questão”, de Nuno Ramos, ${ }^{18}$ que a escritura toca o limite da performance:

Me enrolei no cobertor felpudo e cochilei imediatamente, restos de tartaruga em meus cinco sentidos. Quando acordei a luz da tarde entrava pelas frestas das janelas fechadas. O lobo estava ali dentro, deitado bem perto, fora da jaula.

Enrolei e estendi o cobertor, sacudindo a minha isca feito cobra de pano, mas o lobo não se moveu. Joguei o tecido inteiro, aberto, sobre ele, que se irritou afinal, rosnando e abocanhando a ponta.

Os excertos de Nuno Ramos praticamente coincidem com a performance do artista alemão Joseph Beuys, intitulada I like America and America likes me, de $1974 .{ }^{19}$ No entanto, referência à parte, Nuno Ramos, em “O velho em questão”, vale-se da animalidade enquanto uma condição performativa da escrita. Essa mesma condição de Nuno Ramos

${ }^{16}$ CANGUILHEM. Escritos sobre a medicina, p. 18.

${ }^{17}$ CANGUILHEM. Escritos sobre a medicina, p. 18 refere-se ao cirurgião Jean Deveaux (16491729) e o seu estudo Le médecin de soi-même ou l'art de conserver la santé par l'instinct.

${ }^{18}$ RAMOS. O pão do corvo, p. 25.

${ }^{19}$ A ação de Joseph Beuys, que aconteceu de 21 a 25 de maio de 1974, na Galeria René Block, consistia na convivência do artista com um coiote selvagem. Inicialmente Beuys utilizou um cajado e um manto de feltro para mediar sua relação com o coiote. 
aconteceu no breve texto escrito pelo artista e publicado no dia 17 de outubro de 2010, no jornal Folha de S.Paulo:

Procurei intencionalmente matar três urubus de fome e de sede no prédio da Bienal de São Paulo. Pus ali imensas latas cheias de tinta escura, para que se afogassem, além de espelhos, para que batessem a cabeça durante o voo. Construí túneis de areia preta, para que entrassem sem conseguir sair, morrendo ali dentro. E, para forçá-los a voar, costumo lançar rojões em sua direção. ${ }^{20}$

O texto de Nuno Ramos, publicado na Folha de S.Paulo, desloca-se de "O velho em questão"; ele se desenvolve como se dentro de um sonho humano, envolvendo uma crueldade que aciona sua memória plástica: tinta escura, espelhos, túneis de areia preta e rojões. É diante desse texto que é possível se deparar com outro espaço negro, ainda mantendo o sentido de Roger Caillois, a indistinção entre organismo e meio. No entanto, há uma arquitetura ou uma obra dentro do texto que não coincide com a instalação Bandeira branca, que esteve na $29^{\text {a }}$ Bienal de São Paulo. A imagem do texto é mais cruel que a obra instalativa. E tal violência semântica, que é uma provocação do artista, em nenhum momento foi questionada. Tem-se aí a inscrição de uma distância pautada apenas entre o dizer e o mostrar? Ou a presença real do animal rearticula outras camadas imemoriais no animal humano?

Além da proximidade de Nuno Ramos com a ação de Joseph Beuys, pode-se pensar na sequência de três imagens do artista Rodrigo Braga intitulada Comunhão. As imagens reiteram a discussão do "signo cego" das cavernas de Lascaux que coincidem com a condição da poesia segundo Bataille:“este também é o preço que é preciso pagar se nós não quisermos nos fechar aos ensinamentos silenciosos da caverna." ${ }^{21}$ Talvez seja dessa escuridão que se origine, sob o traço da animalidade, uma espécie bandeira branca entre a vasta trajetória da distinção irreconciliável - um abismo - entre os animais humanos, entre o animal humano e o animal não humano.

A animalidade, esse signo cego no espaço negro, talvez seja o ato do corpo de forçar a linguagem, a exigência de alterar os limites que aqui não se sabe quais, do pensamento animal articulado enquanto hipótese de determinadas situações de abandono de si, uma

\footnotetext{
${ }^{20}$ RAMOS. Bandeira branca, amor, p. 2.

${ }^{21}$ BATAILLE. Lascaux ou la naissance de l'art, 1955, p. 126.
} 
deriva radical frente ao estranho inconsciente que as gramáticas, os dicionários, as anatomias, enfim, que as imagens exibem e insistem em manter - não sem um desconforto - sob os auspícios da palavra “animal”.

\section{Résumé}

Le présent essai discute les aspects formels de la ressemblance et de l'animalité ayant comme point de départ l'œuvre de l'écrivain et plasticien brésilien Nuno Ramos.

\section{Mots-clés}

Ressemblance, animalite, metamorphose, litterature, art contemporain

\section{REFERÊNCIAS}

BATAILLE, Georges. Lascaux ou la naissance de l'art. Paris: Skira, 1955.

BATAILLE, Georges. Lascaux ou la naissance de l'art. Paris: Skira, 1996.

BATAILLE, Georges. La felicidad, el erotismo y la literatura. Trad. Silvio Mattoni. Ensayos 1844-1961. Buenos Aires: Adriana Hidalgo, 2008.

BENJAMIN, Walter. A doutrina das semelhanças. In: . Obras escolhidas. Magia e técnica, arte e política. Trad. Sérgio Paulo Rouanet. São Paulo: Brasiliense, 1996. p. 108113.

BLANCHOT, Maurice. La amistad. Trad. J. A. Doval Liz. Madrid: Trotta, 2007.

BORER, Alain. Joseph Beuys. Trad. Betina Bischot e Nicolás Campanário. São Paulo: Cosac Naify, 2001.

BRAGA, Rodrigo. More force than necessary. Belgique: In Flanders Fields Museum, 2010.

CAILLOIS, Roger. El mito y el hombre. Trad. Roger Ferreiro. México: Fondo de Cultura Económica, 1998.

CANGUILHEM, Georges. Escritos sobre a medicina. Trad. Vera Avellar Ribeiro. Rio de Janeiro: Forense Universitária, 2005.

DERRIDA, Jacques. O animal que logo sou (a seguir). Trad. Fábio Landa. São Paulo: Unesp, 2004.

DIDI-HUBERMAN, Georges. La ressemblance informe ou le gai savoir selon Georges Bataille. Paris: Macula, 2005. 
FREUD, Sigmund. O mal-estar na cultura. Trad. Renato Zwick. Porto Alegre: L\&PM, 2010.

RAMOS, Nuno. Cujo. São Paulo: Editora 34, 1997.

RAMOS, Nuno. O pão do corvo. São Paulo: Editora 34, 2001.

RAMOS, Nuno. Ó. São Paulo: Iluminuras, 2009.

RAMOS, Nuno. Bandeira branca, amor. Folha de S.Paulo, São Paulo, Ilustríssima, 17 out. 2010. 